\title{
LIPUTAN PERPUSTAKAAN DALAM SURAT KABAR DI INDONESIA (BERITA TENTANG PERPUSTAKAAN DI SURAT KABAR REPUBLIKA, KOMPAS, KEDAULATAN RAKYAT, DAN BERNAS BULAN NOPEMBER 2006 - APRIL 2007) \\ Oleh : Sukirno ${ }^{1} \&$ Hermin Indah Wahyuni ${ }^{2}$
}

\begin{abstract}
Library as one of information systems has vital role in collecting, arranging, and spreading information to public who need it. Library has strategic position in learning public because its role is to collect, arrange, and prepare knowledge recording to read and study. There haven't been many user come and utilize the facilities in library. One of factors is lack of promotion or socialization to public about library through mass media, in this case coverage in newspaper.

To get general illustration about tendency of coverage with theme library and information literacy in Republika, Kompas, Kedaulatan Rakyat, and Bernas November 2006-April 2007 edition.

This research has purpose to get general illustration about the tendency of coverage of library theme in Republika, Kompas, Kedaulatan Rakyat, and Bernas, November 2006 - April 2007.Research method in this research is descriptive qualitative method which coverage content of library in the four newspaper Republika, Kompas, Kedaulatan Rakyat, and Bernas. Data from research will be process and analyzed by category analysis and showed descriptively. Research data in the four newspaper, Republika, Kompas, Kedaulatan Rakyat, and Bernas showed that the amount of library coverage is still low. Based of more detailed category, those are (1) library management, (2) library facilities and medium, (3) library technology, (4) librarians, (5) non-substantive, (6) information literacy, the most amount of coverage is on Kedaulatan Rakyat. Coverage theme that often covered the four newspaper is just on coverage category which is not connected directly with library, that is non-subtantive coverage. In this case, it is connected with book information, consist of resensi or book promotin. Meanwhile, for information literacy coverage is placed in second range in its coverage.
\end{abstract}

Key word: Library Coverage, Information Literacy, Newspaper

1. Pustakawan UGM

2. Dosen Fakultas Ilmu Sosial \& Politik UGM

\section{Latar Belakang}

Perpustakaan mempunyai peran penting di masyarakat. Di perpustakaan tersedia berbagai macam dan jenis informasi yang dapat dimanfaatkan masyarakat sesuai dengan kebutuhannya. Hal ini didukung dengan fungsi perpustakaan, pertama perpustakaan berfungsi merekam pengetahuan, sebagai tempat untuk mengakumulasi rekaman pengetahuan manusia pada jamannya, dengan tujuan untuk mengingat dan menyampaikan pengetahuan. Dengan adanya akumulasi pengetahuan muncul peluang untuk melakukan pendidikan dan penelitian. Kedua, perpustakaan mempunyai fungsi pendidikan dan penelitian. Hasil pendidikan dan penelitian ditulis dalam bentuk buku, artikel dan sebagainya kemudian dikelola di perpustakaan untuk dapat digunakan kembali dalam proses pendidikan dan penelitian. Ketiga, perpustakaan berfungsi kebudayaan tempat untuk menyimpan hasil dari budaya masyarakat. Keempat perpustakaan berfungsi rekreasi yang dimaksud rekreasi disini adalah suatu proses yang dilakukan seseorang dalam menciptakan ide-ide baru atau menjadi kreatif kembali dari koleksi-koleksi yang tersedia di perpustakaan (Sudarsono, 2006). 
Namun secara realita, dukungan masyarakat terhadap perpustakaan masih sangat rendah, baik itu di perpustakaan perguruan tinggi, perpustakaan umum, perpustakaan sekolah, atau perpustakaan khusus. Hal ini dapat dilihat dari rendahnya apresiasi, kunjungan, dan pemanfaatan fasilitas koleksi di perpustakaan.

Promosi atau sosialisasi kepada masyarakat tentang perpustakaan melalui media massa dalam hal ini liputan di surat kabar merupakan cara yang dapat digunakan untuk meningkatkan apresjasj masyarakat. Liputan surat kabar merupakan mekanisme komunikasi persuasif dalam masyarakat dengan memanfaatkan teknik-teknik tertentu dalam hubungan masyarakat. Melalui liputan maka terjadi pertukaran informasj antar perpustakaan dengan pemakaj yang bertujuan memberikan informasi mengenai produk dan jasa yang disediakan oleh perpustakaan serta membujuk pemakai untuk bereaksi terhadap produk dan jasa yang ditawarkan.

Fungsinya surat kabar dapat digunakan untuk membangun opini publik atau mensosialisasikan program atau kegiatan. Disamping itu misi surat kabar juga ikut berpartisipasi dalam proses mencerdaskan kehidupan bangsa. Misi ini sejalan dengan tujuan dari perpustakaan. Pemanfaatan surat kabar sebagai sarana liputan perpustakaan ke masyarakat penting dilakukan dalam rangka membangun apresiasi masyarakat terhadap perpustakaan.

Mencermatj arti pentingnya liputan perpustakaan, maka surat kabar Republika, Kompas, Kedaulatan Rakyat dan Bernas sebagai surat kabar harian nasional dan surat kabar lokal mempunyaj pengaruh dalam mensosialisasikan perpustakaan pada masyarakat.

Melihat keempat surat kabar tersebut yang mempunyai pengaruh luas di masingmasing segmen, yaitu Republika dan Kompas pada tingkat nasional, Kedaulatan Rakyat dan Bernas pada tingkat lokal Yogyakarta. Patut dicermati adalah apakah keempat surat kabar tersebut senantiasa memuat liputan tentang perpustakaan dalam terbitannya. Asumsinya jika surat kabar Republika, Kompas, Kedaulatan
Rakyat, dan Bernas senantiasa memuat liputan tentang perpustakaan, maka akan membangun imej positif di masyarakat tentang perpustakaan. Untuk itu guna mendapatkan gambaran umum mengenai liputan perpustakaan di surat kabar Republika, Kompas, Kedaulatan Rakyat, dan Bernas bulan Nopember 2006 - April 2007, maka penelitian inj dilakukan.

\section{Konsep Penelitian}

Perpustakaan merupakan suatu tempat yang digunakan untuk menyimpan dan melayankan berbagai bentuk dan jenjs informasi yang diatur dengan menggunakan sistem tertentu. Secara prinsip ketersediaan informasi merupakan fokus utama dalam kegiatan di perpustakaan. Selanjutnya informasi tersebut dimanfaatkan masyarakat pengguna untuk memenuhi kebutuhan. Pemanfaatan informasi di perpustakaan sangat dipengaruhi latarbelakang masyarakat, meliputi; literasi, pendidikan, status sosial, dan kebutuhan informasi masyarakat. Sedang liputan surat kabar merupakan salah satu sarana yang digunakan untuk mensosialisasikan kepada masyarakat terhadap fasilitas dan layanan perpustakaan.

Berdasarkan pada pendekatanpendekatan teori yang diungkapkan berkaitan dengan liputan perpustakaan di surat kabar, maka kerangka teori yang digunakan dalam penelitian ini adalah sebagaimana dalam gambar. Penelitian ini dilakukan terhadap liputan perpustakaan di surat kabar. Fokus dalam penelitian ini adalah pada isi liputan surat kabar dan bukan pengaruh liputan terhadap masyarakat. 


\section{Kerangka Konsep Penelitian}

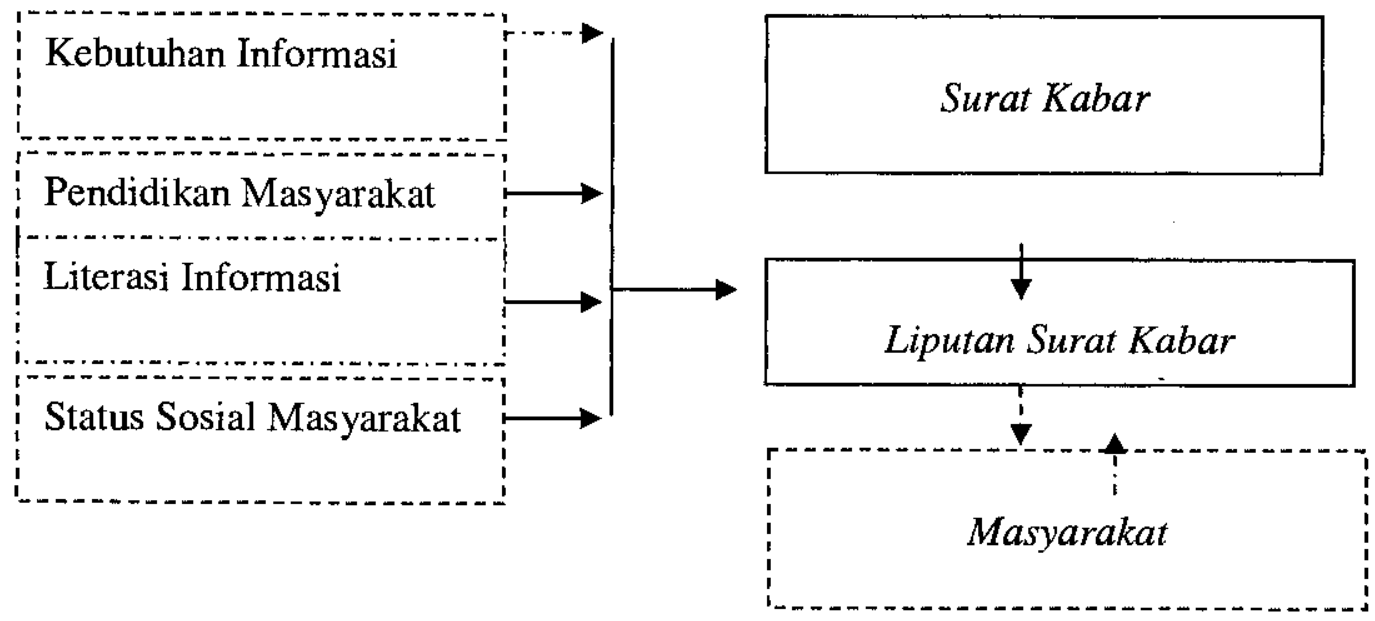

\section{G. Kerangka Penelitian}

Berdasarkan kerangka konsep dan beberapa teori pada tema-tema diatas, maka kerangka penelitian yang peneliti gunakan untuk meneliti liputan perpustakaan di surat kabar adalah:

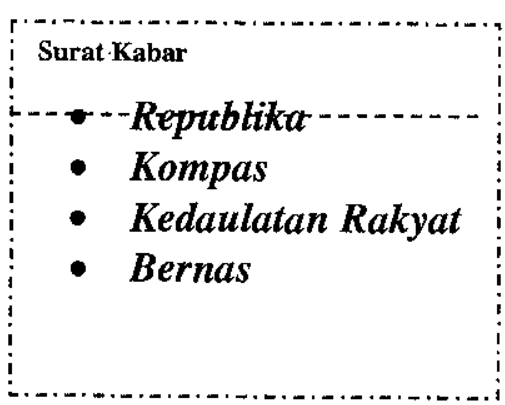

Keterangan :

\section{Karakteristik Tampilan}

1. Jumlah Liputan

2. Panjang Liputan

3. Tipe Liputan

4. Lingkup Liputan

5. Tipe Liputan

6. Narasumber

\section{Karakteristik Isi}

1 Manajemen\& Perpustakaan

2 Sarana \& Fasilitas

3 Teknologi

4 Kepustakawanan

5 Literasi Informasi

6 Non-subtantif
Yang Diteliti

Yang Tidak Diteliti

\section{Cara Penelitian}

Metode penelitian yang digunakan dalam penelitian ini adalah metode deskriptif kualitatif. Mengapa deskriptif kualitatif karena obyek penelitian ini dalam bentuk teks atau narasi/artikel liputan perpustakaan di surat kabar, sehingga data-datanya bukan dalam bentuk numerik atau kuantitatif, Moleong (1995). Walaupun data tersebut nantinya akan disajikan dengan pendekatan kuantitaf. Di samping itu metode ini sesuai dengan tujuan yang hendak peneliti lakukan yaitu untuk mengungkap gejala liputan perpustakaan dalam surat kabar Republika, Kompas, Kedaulatan Rakyat, dan Bernas.

Populasi dalam penelitian ini semua isi liputan perpustakaan yang terbit di surat kabar Republika, Kompas, Kedaulatan Rakyat, dan Bernas dari bulan Nopember 2006 sampai bulan April 2007. Sampel yang diambil dalam penelitian ini adalah halaman yang terdapat 
dalam surat kabar Republika, Kompas, Kedaulatan Rakyat, dan Bernas yang terbit dari bulan Nopember 2006 - April 2007 dengan

Tabel Sebaran Isi Liputan Perpustakaan di Keempat Surat Kabar

pengambilan sampel dilakukan pada minggu ke 1 dan ke 3 dalam tiap bulannya. Kemudian setiap minggu diambil tujuh hari terbitan yaitu dari hari Senin sampai hari Minggu.

Teknik pengumpulan dalam penelitian deskriptif kualitatif ini menitik beratkan pada observasi dan suasana yang alamiah. Dimana data dibedakan menjadi data primer dan data sekunder.

Analisis data yang diperoleh dari penelitian akan diolah dan dianalisis dengan teknik analisis kategori dan ditampilkan secara deskriptif. Analisis data dilakukan terbatas pada teknik pengolahan datanya, seperti pada pengecekan, data dan tabulasi, dalam hal ini sekedar membaca tabel-tabel, grafik-grafik atau angka-angka yang tersedia, kemudian melakukan uraian dan penafsiran.

\section{Hasil dan Pembahasan}

Dalam penelitian ini tidak mudah untuk menentukan kategori isi liputan di surat kabar. Untuk itu guna mendapatkan liputan perpustakaan di keempat surat kabar peneliti menetapkan kategori-kategori liputan perpustakaan. Hal ini dilakukan penelitian karena peneliti tidak menemukan kategori-kategori liputan perpustakaan yang dapat dijadikan acuan dalam mengkaji liputan perpustakaan pada surat kabar di Indonesi. Sebagaimana dikatakan Flournoy (1989) mengutip pendapat Stempel (1981) peneliti memutuskan untuk menentukan kategori-kategori tersendiri yang digunakan analisi jika belum ada kategori yang menjadi acuan. Adapun kategori-kategori liputan yang peneliti tentukan, meliputi; (1) manajemen perpustakaan, (2) sarana dan fasilitas perpustakaan, (3) teknologi informasi perpustakaan, (4) kepustakawanan, (5) literasi informasi, dan (6) non-subtantif. Berdasarkan pada kategori liputan perpustakaan di surat kabar Republika, Kompas, Kedaulatan Rakyat, dan Bernas ditemukan 44 item liputan perpustakaan dengan rincian sebagaiman tabel berikut.

\begin{tabular}{|l|l|l|l|l|l|} 
Liputan & Republika & Kompas & $\begin{array}{l}\text { Kedaulatan } \\
\text { Rakyat }\end{array}$ & Bernas & Jumlah \\
\hline $\begin{array}{l}\text { Manajemen } \\
\text { Perpustakaan }\end{array}$ & 0 & 2 & 5 & 1 & 8 \\
$\begin{array}{l}\text { Sarana \& Fasilitas } \\
\text { Perpustakaan }\end{array}$ & 1 & 0 & 1 & 1 & 3 \\
$\begin{array}{l}\text { Teknologi } \\
\text { Perpustakaan }\end{array}$ & 1 & 2 & 1 & 1 & 5 \\
\hline Kepustakawanan & 0 & 0 & 0 & 0 & 0 \\
\hline Non-Substantif & 3 & 8 & 2 & 4 & 17 \\
\hline Literasi Informasi & 3 & 1 & 6 & 1 & 11 \\
\hline
\end{tabular}

Sumber : Data primer

Berdasarkan tabel diatas menempatkan liputan non-subtantif pada urutan pertama, yaitu 8 item $72,2 \%$. Berdasarkan pada temuan diatas dapat dikatakan bahwa isi liputan perpustakaan di keempat surat kabar Republika, Kompas, Kedaulatan Rakyat, dan Bernas terdapat perbedaan yang cukup bervariasi, yaitu liputan pada non-subtantif mendapatkan porsi liputan yang lebih besar. Kemudian literasi informasi juga menjadi perhatian liputan surat kabar. Kedua kategori tersebut bisa jadi menurut surat kabar mempunyai nilai jual pada khalayak sehingga senantiasa perlu diliput. Dikategorikan liputan non-subtantif jika liputan tersebut tidak berhubungan langsung dengan perpustakaan, tetapi mempunyai pengaruh secara tidak langsung di perpustakaan, yaitu meliputi; UU perpustakaan, informasi buku, dan lain-lain. Termasuk dalam kategori informasi buku antara lain; liputan tentang resensi/bedah buku, penulisan buku, dan penerbitan buku. Promosi buku biasanya dilakukan oleh penerbit sebagai sarana pemasaran. Sehingga wajar jika kategori ini sering diliput surat kabar, karena adanya usaha proaktif penerbit untuk memasarkan produknya. Berdasarkan data tersebut terjawab mengapa liputan keempat surat kabar pada sesuatu yang justru subtantif dan berhubungan langsung dengan perpustakaan sedikit liputanya, jika dibandingkan dengan hal-hal yang nonsubtatif. Hal ini dapat terjadi ada beberapa sebab, satu diantara yang dapat digunakan untuk menjawab pertanyaan tersebut yaitu perpustakaan belum secara proaktif untuk memasarkan atau promosi terhadap produk yang 
ada di perpustakaan dibandingkan promosi buku, sehingga surat kabar tidak mengetahui hal-hal menarik apa di perpustakaan yang dapat disajikan kepada khalayak. Berbeda dengan informasi buku, karena ada upaya-upaya dari penerbit untuk memasarkan atau mempromosikan pada khalayak bekerja sama dengan surat kabar. Bahkan dari redaksi surat kabar ada kebijakaan khusus tentang rubrik atau kolom yang dibuat untuk rensensi atau bedah buku. Sebagaimana di surat kabar Kompas pada setiap hari Sabtu terdapat kolom resensi buku dengan nama rubrik Pustakaloka, dimana dalam kolom Pustakaloka disedikan satu halaman khusus untuk ruang perbukuan. Isi rubrik Pustakaloka, meliputi; resensi buku, liputan perbukuan, dan pembuatan indeks penjualan buku. Rubrik ini muncul dilatarbelakangi adanya keprihatinan jajaran pimpinan redaksi Kompas karena belum adanya liputan tentang perbukuan pada surat kabar di Indonesia. Bahkan dalam rubrik Pustakaloka ditanggani langsung dari litbang Kompas.

Gambar : Isi Liputan di Keempat Surat Kabar

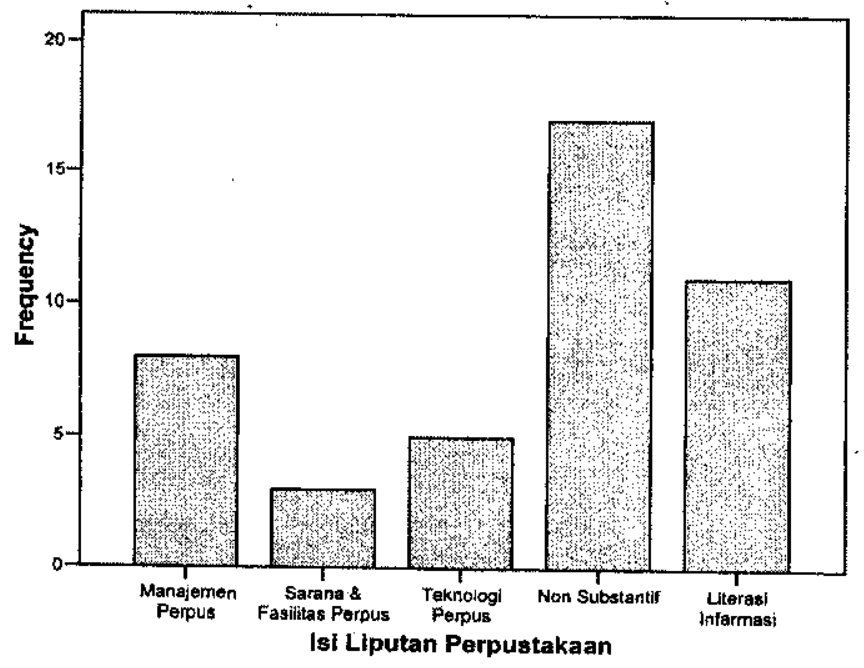

Sumber : Data Primer

Kemudian isi liputan perpustakaan dilihat dari faktor lain, yaitu panjang pendeknya liputan, lingkup liputan, tipe liputan, narasumber liputan, dan jenis liputan menunjukkan variasi yang beragam. Surat kabar Republika dan Kompas sebagai surat kabar nasional menunjukkan liputan perpustakaan di kedua surat kabar tersebut cenderung dalam meliput tema perpustakaan dengan liputan panjang dan tipe liputan langsung. Sedangkan surat kabar Kedaulatan Rakyat dan Bernas yang termasuk surat kabar lokal atau daerah cenderung meliput tema perpustakaan dengan liputan pendek dengan tipe liputan press release. Hal ini menunjukkan surat kabar Kedaulatan Rakyat dan Bernas sebagai surat kabar lokal atau daerah meliput perpustakaan lebih menonjolkan aspek kuantitas yaitu liputan press release. Jenis liputan press release di surat kabar Kedaulatan Rakyat dan Bernas merupakan hasil kegiatan perpustakaan di daerah. Selanjutnya jika dilihat dari aspek lingkup liputan perpustakaan menunjukkan bahwa surat kabar Republika dan Kompas isi liputan perpustakaan cenderung lingkup nasional dan internasional, sedangkan untuk surat kabar Kedaulatan Rakyat dan Bernas cenderung lingkup liputan perpustakaan pada lokal atau daerah. Fakta ini sejalan dengan pendapat Flournoy (1989) dari Victor J. Danilov bahwa surat kabar daerah memuat liputan-liputan lokal dari pada liputan-liputan nasional. Liputan ini dilakukan karena kecenderungan masyarakat daerah untuk membaca tentang orang dan tempat yang dikenalnya, serta hal-hal yang menyangkut dirinya di daerah.

$\begin{array}{llr}\text { Berkaitan } & \text { dengan } & \text { isi liputan } \\ \text { perpustakaan } & \text { tentang literasi informasi }\end{array}$
menempati urutan kedua setelah liputan nonsubtantif. Hal ini menunjukkan bahwa literasi informasi merupakan isu aktual dan menarik yang layak disajikan ke khalayak oleh surat kabar. Liputan literasi informasi berkaitan dengan kategori minat baca dimuat dalam surat kabar Republika dan Kedaulatan Rakyat masingmasing 2 item $40 \%$, kategori pedidikan pemakai tidak ada surat kabar yang meliput $0 \%$, kategori pemanfaatan informasi diliput surat kabar Kedaulatan Rakyat 2 item $66,6 \%$ dan surat kabar Republika 1 item 33,3\%, untuk kategori lain-lain dimuat surat kabar Kompas dan Kedaulatan Rakyat masing-masing 50\%. Temuan tersebut menunjukkan keempat surat kabar mempunyai perhatian pada literasi informasi. Hal ini wajar sebab isu literasi informasi sudah menjadi 
perhatian banyak pihak sehingga banyak yang berkepentingan. Namun sayang justru pemerintah sebagai penentu kebijakan belum memberikan perhatian secara serius terhadap literasi informasi. Hal ini bisa di lihat belum adanya program dari pemerintah, baik pusat maupun level daerah yang merumuskan program-progam untuk meningkatkan literasi informasi masyarakat. Berbeda dengan negaranegara lain, Malaysia misalnya. menurut Saad (2006) rumusan secara sistematis literasi menjadi tanggung jawab kementrian pendidikan, dan menjadi acuan standar untuk lembaga pendidikan dari level sekolah sampai perguruan tinggi. Dari sini wajar kalau tingkat literasi informasi masyarakat Indonesia berada di bawah negaranegara lain. Pengaruh rendahnya literasi ini adalah rendahnya kesadaran masyarakat untuk berkunjung ke perpustakaan dan memanfaatkan informasi di prpustakaan.

\section{Kesimpulan dan Saran}

\section{A. Kesimpulan}

Berdasarkan hasil penelitian liputan perpustakaan di keempat surat kabar tersebut paling banyak terdapat pada surat kabar Kedaulatan Rakyat. Kemudian jika dilihat dari isi liputan perpustakaan di keempat surat kabar tersebut yang sering diliput adalah pada kategori liputan yang tidak berhubungan langsung dengan perpustakaan, yaitu liputan non-subtantif dan literasi informasi. Masuk dalam kategori liputan non-subtantif, yaitu hal-hal yang berkaitan dengan informasi buku yang terdiri dari resensi atau promosi buku. Bahkan di surat kabar Kompas pada setiap hari Sabtu terdapat kolom resensi buku dengan nama rubrik Pustakaloka, dimana dalam kolom Pustakaloka disedikan satu halaman khusus untuk ruang perbukuan. Isi rubrik Pustakaloka, meliputi; resensi buku, liputan perbukuan, dan pembuatan indeks penjualan buku. Rubrik ini muncul dilatarbelakangi adanya keprihatinan jajaran pimpinan redaksi Kompas karena belum adanya liputan tentang perbukuan pada surat kabar di Indonesia dan rubrik Pustakaloka ditanggani langsung dari litbang Kompas.
Kemudian isi liputan perpustakaan dilihat dari faktor lain, yaitu panjang pendeknya liputan, lingkup liputan, tipe liputan, narasumber liputan, dan jenis liputan menunjukkan variasi yang beragam. Surat kabar Republika dan Kompas sebagai surat kabar nasional menunjukkan liputan perpustakaan di kedua surat kabar tersebut cenderung dalam meliput tema perpustakaan dengan liputan panjang dan tipe liputan langsung. Sedangkan surat kabar Kedaulatan Rakyat dan Bernas yang termasuk surat kabar lokal atau daerah cenderung meliput tema perpustakaan dengan liputan pendek dengan tipe liputan press release. Hal ini menunjukkan surat kabar Kedaulatan Rakyat dan Bernas sebagai surat kabar lokal atau daerah meliput perpustakaan lebih menonjolkan aspek kuantitas yaitu liputan press release. Jenis liputan press release di surat kabar Kedaulatan Rakyat dan Bernas merupakan hasil kegiatan perpustakaan di daerah. Selanjutnya jika dilihat dari aspek lingkup liputan perpustakaan menunjukkan bahwa surat kabar Republika dan Kompas isi liputan perpustakaan cenderung lingkup nasional dan internasional, sedangkan untuk surat kabar Kedaulatan Rakyat dan Bernas cenderung lingkup liputan perpustakaan pada lokal atau daerah. Fakta ini sejalan dengan pendapat Flournoy (1989) dari Victor J. Danilov bahwa surat kabar daerah memuat liputan-liputan lokal dari pada liputan-liputan nasional. Liputan ini dilakukan karena kecenderungan masyarakat daerah untuk membaca tentang orang dan tempat yang dikenalnya, serta hal-hal yang menyangkut dirinya di daerah.

Hal lain, berkaitan dengan liputan literasi informasi pada keempat surat kabar Republika, Kompas, Kedaulatan Rakyat, dan Bernas. Liputan literasi informasi mendapat perhatian dalam liputan keempat surat kabar, yaitu menempati pada urutan kedua dalam liputan setelah liputan non-subtantif. Liputan literasi informasi yang banyak diliput adalah kategori minat baca. Hal ini menunjukkan keempat surat kabar mempunyai perhatian terhadap literasi informasi, ini merupakan sesuatu positif yang perlu dukungan semua pihak. Hal ini wajar sebab isu literasi informasi sudah menjadi perhatian 
banyak pihak sehingga banyak yang berkepentingan.

\section{B. Saran}

Data penelitian yang berkaitan dengan liputan perpustakaan di keempat surat kabar dalam penelitian ini merupakan sebuah fakta bahwa hubungan perpustakaan dengan surat kabar belum terjalin dengan baik. Hal ini dapat dilihat dari jenis liputan perpustakaan di surat kabar Republika, Kompas, Kedaulatan Rakyat, dan Bernas di mana liputan non-subtantif lebih banyak diliput, sedang hal-hal subtantif yang berkaitan dengan perpustakaan secara langsung sedikit diliput keempat surat kabar. Bagaimanapun surat kabar mempunyai peran atau andil dalam mensosialisasikan, bahkan membangun imej perpustakaan pada masyarakat. Untuk itu pengelola atau manajemen perpustakaan perlu secara aktif untuk bekerja sama atau melakukan promosi dengan atau melalui surat kabar, agar aktivitas atau kegiatan perpustakaan senantiasa dapat diliput surat kabar, sehingga produk jasa yang ada di perpustakaan dapat diketahui oleh masyarakat.

Selanjutnya peneliti menyadari, bahwa penelitian ini masih sebatas penelitian deskriptif kualitatif dan banyak hal yang belum terjaring dalam penelitian ini. Untuk itu penelitian lanjutan mengenai liputan perpustakaan perlu untuk dilakukan agar dapat diperolah data lebih komprehensif mengenai hubungan surat kabar dan perpustakaan. Kemudian untuk membangun tradisi penelitian di lingkungan pustakawan atau mahasiswa ilmu perpustakaan perlu dibangun pusat studi perpustakaan. Sehingga penelitian tentang perpustakaan dan informasi akan banyak dihasilkan dengan berbagai jenis pendekatan atau metode penelitian, harapannya melalui penelitian ini perkembangan ilmu perpustakaan akan berkembang pesat. Dengan demikian ilmu perpustakaan akan sejajar dengan bidang keilmuan lainnya.

\section{DAFTAR PUSTAKA}

Abrar, Ana Nadhya. 1997. Pelecehan dan Kekerasan

Seksual: Analisis Isi Surat Kabar Indonesia.
Yogyakarta: Pusat Penelitian Kependudukan UGM.

2007. Memelihara Eksistensi KR. Kedaulatan Rakyat, Halaman 14, Kolom 3-5.

Bryson, Jo. 1990. Effective Library and Information Centre Management. Vermont: Gower Publishing Company.

Bungin, Burhan. 2003. Erotika Media Massa, Surakarta: Muhammadiyah University Press.

Depkominfo. 2006. Menyingkap Profesionalisme Kinerja Surat Kabar di Indonesia. Jakarta: Krayon Grafika.

Djuroto, Totok. 2002. Manajemen Penerbitan Pers. Bandung: PT Remaja Rosdakarya.

Ernawam, Yusuf, et.al. 1992. Pola Perilkau Kejahatan Wanita: Analisis Terhadap Isi Media Massa di Jawa Timur. Surabaya: Lembaga Penelitian Universitas Airlangga.

Flournoy, Don Michael. 1989. Analisis Isi Suratkabar-Suratkabar Indonesia. Yogyakarta: Gadjah Mada University Press.

Handoko, T. Hani. 1993. Manajemen II. Yogyakarta: BPFE.

Hasan, M. Iqbal. 2002. Metodologi Penelitian dan Aplikasinya: Pokok-Pokok Materi. Jakarta: Ghalia Indonesia.

Ismail, Taufiq. 2005. Tragedi Nol Buku, Tragedi Kita Bersama. Pekanbaru-Riua: Rapat Kerja Pusat XIII dan Seminar Ilmiah Nasional IPI, 31 Mei -3 Juni.

Irawati, Indira. 2005. Penguasaan Information Literacy Mahasiswa Program Studi Ilmu Perpustakaan, Skripsi Fakultas Ilmu Pengetahuan Budaya, Universitas Indonesia.

Kartosedono, S. 1995. Perpustakaan sebagai Lembaga Pendidikan dan Sarana Mencerdaskan Masyarakat Bangsa. Media Pustakawan 2(20):4-5.

Kurniawati, R. Deffi. 2007. Peranan perpustakaan dalam Meningkatkan Minat Baca Masayarakat: Survei pada Perpustakaan 
Umum Kotamadya Jakarta Selatan. Berkala Ilmu Perpustakaan dan Informasi, III(7);1-11.

Moleong, Lexy J. 1995. Metodologi Penelitian Kualitatif. Bandung: PT Remaja Rosdakarya.

NS., Sutarno. 2006. Perpustakaan dan Masyarakat. Denpasar: Konggres IPI Ke-X.

Qalyubi, Syihabuddin, et.al. 2003. Dasar-Dasar Ilmu Perpustakaan dan Informasi. Yogyakarta: IPPI, Fakultas Adab UIN Sunan Kalijaga.

Saad, Mohd Sharif Mohd. 2007. Information Literacy In Malaysia: Trends, Development and Challenges, Konggres IPI Ke-X, Denpasar.

Sanderson, Ralph. (2006). The Role of Developed Countries to Support Information Literacy in Developing Countries. Denpasar: Kongress IPI $\mathrm{Ke}-\mathrm{X}$.

Santana K., Septiawan. (2005). Jurnalisme Kontemporer. Jakarta: Yayasan Obor Indonesia.

Syahputra, Iswandi. 2006. Jurnalistik Infotainment: Kancah Baru Jumalistik dalam Industri Televisi. Yogyakarta: Ufa.

Suciati, Uminurida. 2007. Manfaat Information Literacy (Literasi Informasi) bagi Pustakawan. Media Informasi Vol. XVI, No.2, p. 10-17.

Sudibyo, Agus. 2001. Politik Media dan Pertarungan Wacana. Yogyakarta: Lkis.

Sudarsono, Blasius, 2006. Mencari Akar Kepustakawanan Indonesia, Visi Pustaka: 8(1).

Sugiyono.2001. Metode Penelitian Administrasi. Bandung: CV Alfabeta.

Surachmad, Winarno. 1978. Pengantar Penelitian Ilmiah, Dasar, Metode dan Teknik. Bandung: Tarsito.

Surabaya Post. 1992. Politik Redaksional: Editorial Policy. Surabaya: Produk Media.
Sulistyo-Basuki. 1993. Pengantar Ilmu Perpustakaan. Jakarta: PT Gramedia Pustaka Utama.

Sudiarto. 2006. Persepsi tentang Minat Baca di Indonesia. Media Perpustakaan, Volume 13, No. 1 dan 2.

Priyanto, Ida Fajar. 2007. PERPUSTAKAAN UNTUK PENGEMBANGAN MASYARAKAT : Informasi Bukan Hanya Komoditi Ekonomi. http://lib.ugm.ac.id/exec.php?app=berita\&act= detail\&id $=66$.

Wall, Terry. 1999. Availability, Accessibility, and Demand for Recommended Books in Academic Libraries. Journal of Librarianship and Information Science, 31 (3), pp. 145-151.

Winarko, Heri. 2000. Medeteksi Bias Berita: Panduan untuk Pemula. Yogyakarta: Kajian dan Layanan Informasi untuk Kedaulatan Rakyat. 